\title{
Steviaside Containing Plant as Deconstractive (Degradative) Agent for Persistent Organic Pollutants
}

\author{
Khamid U. Khodjaniyazov, Nazira K. Khidirova, Nuridin I. Mukarramov, Mashrab M. Khakimov, \\ Barot A. Urakov, Khusnutdin M. Shakhidoyatov
}

Institute of the Chemistry of Plant Substances, Academy of Sciences of the Republic of Uzbekistan, Tashkent, Uzbekistan. Email: hamid_khodjaniyazov@yahoo.com

Received May $21^{\text {st }}, 2012$; revised June $17^{\text {th }}, 2012$; accepted July $13^{\text {th }}, 2012$

\begin{abstract}
Steviaside containing plant extracts have been used for degradation of persistent chloroorganic pesticides. Reactions between DDT and Steviaside or sum of extractive substances isolated from ground up part of plant Stevia were studied to give of less toxic DDE. Herein researches on studying interaction sum of polysaccharides of Stevia with DDT in various ratios resulted also. The GC-MS and GLC methods were used for analyzing degradation degree of pesticides and to determine obtained compounds. Treat HCCH by water extract of Stevia basically formed tetrachlorocyclohexadiene $(\mathrm{HCH})$ with $86.9 \%$ yield and in particularly formed of tri-, tetrachlorobenzenes. The HCH formed in $79.7 \%$ on treat pesticide by $80 \%$ Steviaside. Degradation of HCCH and DDT by water extract of Stevia in a presence of anabasine in a ratio of 2:1:1 occur to degrade of $\mathrm{HCCH}$ up to $70 \%-80 \%$, and DDT on $25 \%-30 \%$.
\end{abstract}

Keywords: Chlorinated Pesticides; Extracts of Stevia; Steviaside; Degradation

\section{Introduction}

Polychlorinated organic pesticides (POP) are well-known recalcitrant environmental pollutants. Although the metabolism of the POPs has been intensively studied, very little is known about their mechanism of toxicity in living organisms or how they are degraded in water and soil. We have examined interaction between POPs and Steviaside, also its analogical compounds.

The widespread use of agricultural pesticides in many countries resulted in a serious pollution of the environment (soil, water and atmosphere). Persistent halogenated pesticides such as DDT, lindane, heptachlor, pentachlorophenol, aldrin, keltan and their several combined derivatives were used in large scale due to their efficiency and non-specificity. Moreover, DDT and hexachlorocyclohexane $(\mathrm{HCH})$ were used as effective pesticides for treatment of plant seeds, soil, and crops, and in livestock production, as well as disinfectants against bugs, mosquitoes, flies and other harmful insects for household use.

Purpose of this work was study of degradation of persistent chloroorganic pesticides by using plant extracts, which contain Steviaside.

Air dried plant material was extracted by various solvents at room temperature by method of standing and boiling water extracts. There were isolated polysaccharides from the plant of Stevia and Steviaside with $80 \%$ purity [1].

Possibility of degradation of chloroorganic pesticides by plant extracts, such as extractive compounds of the plant Stevia and alkaloid containing plant extracts were shown as the result [2-5].

\section{Extraction of Ground up Part of Plant Stevia}

An optimal condition for extraction of the plant Stevia finds by following procedure. It was studied influence from the degree of crushing of plant material, which was dried at room temperature in a shadow. For this purpose there were studied investigations with crushed and none crushed dry materials. All of experiments were done in the analogical conditions: $10 \mathrm{~g}$ crushed and none crushed lives extracted with ethanol by the method of insisting. Obtained results given in Table 1.

As shown in Table 1 in the case of extraction of none crushed lives, at first, it needs to use much amount solvent, at second, contact of particles with solvent is low, and so yield of sum of extractive compounds are relative small. Littered filters at a moment of grinding create inconvenience in extraction process. Optimal variant for obtaining extractive compounds were crushing up to 2.0 $3.0 \mathrm{~mm}$.

Another factor which influence to extraction process is choice of hydromodule. So we have done investigations 
Table 1. Influence of crushing degree of the raw materials (leaves) to the yield of extractive compounds.

\begin{tabular}{ccc}
\hline No & $\begin{array}{c}\text { Size of fraction (pass through a sieve } \\
\text { with a hole diameter of, mm) }\end{array}$ & $\begin{array}{c}\text { Yield of extractive } \\
\text { compounds, \% }\end{array}$ \\
\hline 1 & $0.1-0.5$ & 17.60 \\
2 & $0.5-1.0$ & 17.69 \\
3 & $2.0-3.0$ & 17.75 \\
4 & $4.0-5.0$ & 17.70 \\
5 & $5.0-6.25$ & 17.52 \\
6 & None crushed & 15.00 \\
\hline
\end{tabular}

on selection of the hydromodule value. For this purpose extraction of $10 \mathrm{~g}$ plant material with the value of crushing $2.0-3.0 \mathrm{~mm}$ have done at room temperature at ratio of plant material: a solvent 1:7, 1:10, 1:15 by method of insisting during 12 hours. In this case yields were $16.2 \%$, $17.75 \%$, and $18.1 \%$ correspondently. Obtained results are showed, that in one time extraction by increasing of hydromodule yield increase also. For full isolation we use tree times extraction at hydromodule 1:6, 1:5, 1:4 (summary hydromodule 1:15). Yield of extractive compounds were $18.4 \%$.

\section{Degradation of Chloroorganic Pesticides by Extracts of Stevia}

It is known, that chlorophyll containing extracts have properties for degradation of persistent chloroorganic pesticides [6]. We studied interaction of hexachlorocyclohexane with $80 \%$ Steviaside, sum of polysaccharides and water extracts, isolated from plant Stevia in ratio of pesticide: an extract 1:1, 1:2 at room temperature. Results of carried out searches are given in Table 2.

Data resulted in the Table 2 show that in the cases of polysaccharides, obtained from the plant of Stevia and water extract II, obtained by method of insisting, content of $\mathrm{HCCH}$ in reaction mixture is smaller, than in a case of extract I.

It was shown formation of $\mathrm{HCH}$ as the main product by investigation of degradation with water extracts of Stevia with the $97.2 \%$ yield.

From the given data (Figure 1) it is clear that at interaction of the water extract with pesticide $\mathrm{HCCH}$ is observed formation of tetrachlorocyclohexadiene- $86.9 \%$ $(\mathrm{HCH})$, with small content of tri-, tetrachlorobenzenes. In the case of $80 \%$ Steviaside was observed formation of $\mathrm{HCH}$ with $79.7 \%$ yield, and content of trichlorobenzene was increased up to $20.3 \%$. Obtained results are given in Table 3.

Continuing researches on studying interaction of extract of the plant Stevia with chloroorganic pollutants, it was found, that $96 \%$-ethanol extract is more effective for
Table 2. Interaction of hexachlorocyclohexane with extracts of plant Stevia in $50 \%$-ethanol.

\begin{tabular}{|c|c|c|c|c|c|}
\hline No & Substrate & Reagent & Ratio & Temperature & $\begin{array}{c}\text { Degradation, } \\
\%\end{array}$ \\
\hline 1 & $\begin{array}{c}\text { Water extract I } \\
\text { (without refluxing) }\end{array}$ & $\mathrm{HCCH}$ & $\begin{array}{c}1: 1 \\
10: 1\end{array}$ & $\begin{array}{l}\text { room } T . \\
5 \text { days }\end{array}$ & $15-20$ \\
\hline 2 & $\begin{array}{l}\text { Water extract II } \\
\text { (refluxing) }\end{array}$ & $\mathrm{HCCH}$ & $\begin{array}{c}1: 1 \\
10: 1\end{array}$ & $\begin{array}{l}\text { room } T . \\
5 \text { days }\end{array}$ & $\begin{array}{l}40-50 \\
55-60\end{array}$ \\
\hline 3 & Steviaside $80 \%$ & $\mathrm{HCCH}$ & $1: 1$ & $\begin{array}{l}\text { room } T \text {. } \\
7 \text { days }\end{array}$ & $50-60$ \\
\hline 4 & Polysaccharides & $\mathrm{HCCH}$ & $1: 1$ & $\begin{array}{l}\text { room } T . \\
5 \text { days }\end{array}$ & $50-60$ \\
\hline 5 & Polysaccharides & $\mathrm{HCCH}$ & $2: 1$ & $\begin{array}{l}\text { room } T . \\
7 \text { days }\end{array}$ & $65-75$ \\
\hline
\end{tabular}

Table 3. Influence of Steviaside to degradation of pesticide hexachlorocyclohexane.

\begin{tabular}{cccc}
\hline RT, min & $\mathrm{m} / \mathrm{z}$ & Compound & Relative yield \\
\hline 8.94 & 180 & trichlorobenzene & 0.028 \\
10.03 & 180 & trichlorobenzene & 0.175 \\
21.00 & 217 & $\alpha-\mathrm{HCH}$ & 0.129 \\
22.21 & 217 & $\beta-\mathrm{HCH}$ & 0.014 \\
22.35 & 217 & $\gamma-\mathrm{HCH}$ & 0.587 \\
23.58 & 217 & $\delta-\mathrm{HCH}$ & 0.067 \\
\hline
\end{tabular}

degradation of DDT-65\% - 70\% (Table 4).

Interaction of water extract of plant Stevia with HCCH and DDT were studied at room temperature at stirring during 5 days in the presence of alkaloid anabasine in ratio 2:1:1. Process was controlled by TLC: significant changes did not observe. The mixture was sent for 7 days, after that reaction mixture checked by TLC. In the case of $\mathrm{HCCH}$ degradation was $70 \%-80 \%$, and in case of DDT it was only $25 \%-30 \%$.

Interactions some of extracts of ground up part of plant Stevia (water, aqueous ethanol, ethanol) with $\mathrm{HCCH}$ in the presence of alkaloid Anabasine were studied also. It was determined, that in this case $\mathrm{HCCH}$ is degraded to tetrachlorocyclohexadiene with the yield of $60 \%$.

Interaction of dry crushed of ground up part of plant Stevia, water extract Stevia and $80 \%$ Steviaside with preparative form, which contains $10 \%$ of DDT in ratio of reagents 2:1 in the presence of toluene and aqueous ethanol were studied. Degradation products of DDT were analyzed by TLC and chromato-mass spectra. In this case are formed complex mixture, which contained several products of DDT degradation, such as 1-chloro-2(2chloro-1(4-chlorophenyl)ethylenebenzene, 2,4-dichloro1-(2-chloroethylene)benzene, 1,4-dichloro-2-(2-chloroethyl) benzene, 1,2,2-trichloro-1,4-(chlorophenyl)ethane 


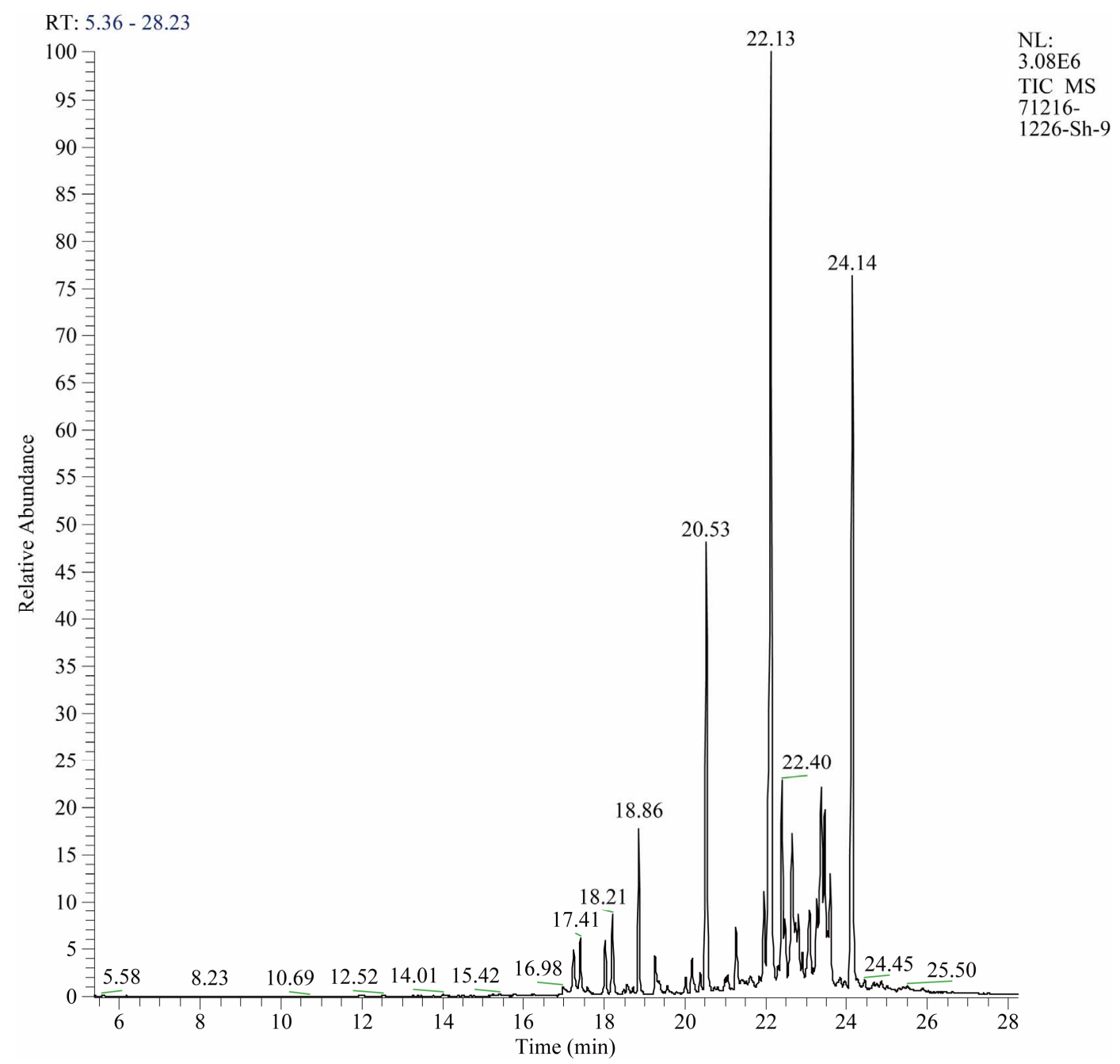

Figure 1. Mass-chromatogram of degradation products of HCCH by water extract of Stevia.

Table 4. Interaction of DDT with extracts of plant Stevia in $50 \%$-ethanol at room temperature.

\begin{tabular}{ccccc}
\hline No & Substrate & Reagent & Ratio & $\begin{array}{c}\text { Degradation, } \\
\%\end{array}$ \\
\hline 1 & $\begin{array}{c}\text { Water extract I } \\
\text { (without refluxing) }\end{array}$ & DDT & $1: 1$ & absent \\
& Water extract II & DDT & $1: 1$ & $35-40$ \\
2 & (refluxing) & & $10: 1$ & $45-50$ \\
& & & $1: 1$ & $40-45$ \\
3 & Steviaside70\% - 80\% & DDT & $10: 1$ & $55-60$ \\
& & & $1: 1$ & $30-35$ \\
4 & $80 \%$-ethanol extract & DDT & $10: 1$ & $35-40$ \\
& & & $1: 1$ & $50-60$ \\
5 & $96 \%$-ethanol extract & DDT & $10: 1$ & $65-70$ \\
\hline
\end{tabular}

and others.

There were studied interaction tetrachlorobenzene (TTCB) with extracts of plant Stevia. It was determined that degradation goes faster then in a case of $\mathrm{HCCH}$ dur- ing of 5 days and more effective is water-ethanol extract where degradation was $85 \%$ - 90\% (Table 5).

Interaction of ground up part and sum of extracted compounds, isolated from plant of Stevia with TTCB in a ratio of $2: 1$ were studied at room temperature in the presence of toluene, benzene, ethanol and aqueous ethanol. Formation of insignificant amount of tri- and dichlorobenzenes were also determined.

\section{Experiments}

\subsection{GC-MS Analysis}

The analysis was performed on gas chromatograph trace GC with ion trap mass-spectrometric detector Polaris Q (Thermo Finnigan). Analysis conditions of: silica capillary column $7 \mathrm{~m} \times 0.32 \mathrm{~mm}$ (DB-5 ms, film thickness 0.25 micron), temperature programming from $60^{\circ} \mathrm{C}(2$ min) to $200^{\circ} \mathrm{C}$ with a rate $6^{\circ} \mathrm{C} / \mathrm{min}$ then to $280^{\circ} \mathrm{C}$ with a rate $8^{\circ} \mathrm{C} / \mathrm{min}$, injector temperature $220^{\circ} \mathrm{C}$, interface$220^{\circ} \mathrm{C}$, electron ionization at energy $70 \mathrm{eV}$, full scan $41-$ 
Table 5. Interaction of tetrachlorobenzene (TTCB) with extracts of plant Stevia at room temperature.

\begin{tabular}{ccccc}
\hline No & Substrate & Ratio & Solvent & Degradation, \% \\
\hline 1 & Polysaccharides & $2: 1$ & $50 \%$-ethanol & $80-81$ \\
2 & Polysaccharides & $2: 1$ & Toluene & $80-85$ \\
3 & $\begin{array}{c}\text { Water-ethanol extract } \\
\text { (refluxing) }\end{array}$ & $2: 1$ & $50 \%$-ethanol & $70-75$ \\
4 & $\begin{array}{c}\text { Water-ethanol extract } \\
\text { (refluxing) }\end{array}$ & $2: 1$ & Toluene & $85-90$ \\
5 & $\begin{array}{c}\text { Sum of glycosides } \\
6\end{array}$ & $2: 1$ & $50 \%$-ethanol & $60-65$ \\
Sum of glycosides & $2: 1$ & Toluene & $80-82$ \\
\hline
\end{tabular}

450 Da. Splitless injection (1:25).

\subsection{GLC Analysis}

GLC analysis carried out on chromatograph "Chromotec Crystal 5000", detector EZD-2 temperature $250^{\circ} \mathrm{C}$, a column: $1500 \mathrm{~mm}$ glass, diameter $3 \mathrm{~mm}$, a nozzle: SE-30, the evaporator temperature is $260^{\circ} \mathrm{C}, \mathrm{V}_{\mathrm{N} 2}=30 \mathrm{ml} / \mathrm{min}$; volume of test $2 \mu \mathrm{l}$.

\subsubsection{Isolation of $\mathrm{HCH}$ from Preparation "Hexachlorane"}

$10 \mathrm{~g} \mathrm{12 \%}$ p.s. pesticide "Hexachlorane" heated up with $100 \mathrm{ml}$ heptane and filtered in a hot kind. A filtrate cooled and a dropped out deposit have filtered. Received hexachlorocyclohexane recrystallized from ethanol. Yield was $80 \%$.

\subsubsection{Isolation of $80 \%$ Purity Steviaside}

From $1000 \mathrm{~g}$ of ground up part of plant Stevia $80 \mathrm{~g}$ dry extract (brown resinous weight) was isolated from it by 96\%-ethanol and filtration fraction which consists of $80 \%$ Steviaside in amount of $4 \mathrm{~g}$ was isolated.

\subsubsection{Preparation of a Standard Steviaside}

In analytical weights weigh $0.05 \mathrm{~g}$ Steviaside and dis-

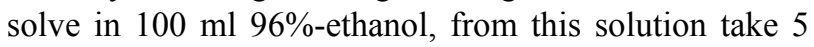
$\mathrm{ml}$ aliquot and lead up 96\%-ethanol up to $50 \mathrm{ml}$.

\subsection{Determining of Steviaside in Ground up Part of Plant Stevia}

\subsubsection{First Method}

On $1.2476 \mathrm{~g}$ crushed raw material I, II till the size of particles $2-3 \mathrm{ml}$ place in a flask capacity $100 \mathrm{ml}$ with a return refrigerator, add $50 \mathrm{ml}$ distilled water and maintain on a boiling water bath $2 \mathrm{hr}$. Cool, filter and wash out water and repeat this operation of 2 more times on 20 min. Extracts unite and drive away under vacuum dry. Extracted with $96 \%$ ethanol of 5 times on $20 \mathrm{ml}$ on a flask capacity $100 \mathrm{ml}$ place the rest on $5 \mathrm{ml}$ from this solution and dilute up to $50 \mathrm{ml}$ with ethanol in a measured flask and measure optical density on SP-46 at $\lambda=$ $330 \mathrm{~nm}$.

Single $96 \%$ ethanol. For preparation of the standard Steviaside weigh $0.05 \mathrm{~g}$ Steviaside and dissolve in 100 $\mathrm{ml}$ of $96 \%$-ethanol, from this solution take $5 \mathrm{ml}$ aliquot and lead up $96 \%$-ethanol up to $50 \mathrm{ml}$. The contents of Steviaside determine under the formula.

\subsubsection{Second Method}

On $1.0 \mathrm{~g}$ crushed raw material I, II till the size of particles $2-3 \mathrm{~mm}$ place in a flask capacity of $100 \mathrm{ml}$ supplied with a return refrigerator, add $50 \mathrm{ml}$ distilled water and maintain on a boiling water bath 2 hours. The cooled mix filter and wash out water and repeat this operation of 2 more times on $20 \mathrm{~min}$. Extracts unite and drive away under vacuum up to $5-10 \mathrm{ml}$. Extracted $96 \%$ ethanol of 5 times on $20 \mathrm{ml}$ and from this solution take the rest on 5 $\mathrm{ml}$ and dilute up to $50 \mathrm{ml}$ with spirit in a measured flask. Quantity of Steviaside determine by a method TLC with photodensitometer. On a plate silica gel without the fluorescent indicator, the size $20 \times 20 \mathrm{~cm}$ rendered on three layers of researched solutions of samples and four tests of the standard Steviaside. System (eluent) - chloroform:methanol:water in the ratio 3:2:0.4, dried up in an exhaust case, spray $10 \%$ a solution of a sulfuric acid and maintain in a drying case at temperature $110^{\circ} \mathrm{C}$ during 5 minutes. $\mathrm{R}_{\mathrm{f}}$ for Steviaside was 0.80 .

\subsection{Extracts of Stevia}

\subsubsection{Fractional Extraction with Ethanol and Aqueous Ethanol of Stevia}

$50 \mathrm{~g}$ a plant material (an elevated part of plant Stevia) with a degree of crushing $2.0-3.0 \mathrm{~mm}$ extracted at room temperature three times at a ratio plant raw material:ethanol 1:6, 1:5, 1:5 insisting within 12 hours. Ethanol extracts united all and have received $550 \mathrm{ml}$ of an extract.

$200 \mathrm{ml}$ of extract I diluted equal volume of water and extracted consistently with gasoline, benzene (neutral substances), ethyl acetate (low-molecular phenolic compounds) and n-buthanole-olygomer phenolic compounds (on $100 \mathrm{ml}$ three times). Every of petrol, benzene, ethyl acetate and n-buthanol extracts united and condensed up to $2 / 3$ volumes and have left in a dark place for the further researches with the purpose of studying degradation chloroorganic pesticides under their action.

\subsubsection{Extraction Ground up Part Plant Stevia}

$10 \mathrm{~g}$ a plant material with a degree of crushing $2.0-3.0$ $\mathrm{mm}$ extracted at room temperature at a ratio plant raw material:ethanol 1:7, 1:10, 1:15 insisting within 12 hours. Thus yield of the sum extracted substances have made $16.2 \%, 17.75 \%, 18.1 \%$ accordingly. 


\subsubsection{Isolation of Water Extract from of Ground up Part of Plant Stevia}

$25 \mathrm{~g}$ of plant material with a degree of crushing of 3.0 $5.0 \mathrm{~mm}$ extracted by water at a ratio 1:6 within $6 \mathrm{hrs}$, three times. Water extracts unite and evaporate before reception of the waterless rest. The rest brownish-the yellow color, looking like dense syrup; at cooling hardens. The yield was $5.4 \mathrm{~g}(21.6 \% \mathrm{I})$.

\subsubsection{Isolation of Water Extract from of Ground up Part of Plant Stevia}

$25 \mathrm{~g}$ plant material with a degree of crushing 3.0 - 5.0 $\mathrm{mm}$ extracted by hot water at a ratio 1:6 within $3 \mathrm{hrs}$, three times. Water extracts unite and evaporate before reception of the waterless rest. The rest brownish-the yellow color, looking like dense syrup; at cooling hardens. The yield was $8.2 \mathrm{~g}(32.8 \% \mathrm{II})$.

\subsubsection{Isolation of Polysaccharides}

For isolation water-soluble polysaccharides free from lipophylic compounds plant material extracted all over again $300 \mathrm{ml}$ cool, then heated water; water extracts summarized and evaporate before reception of the waterless rest. The rest of brown yellow color also looks like dense syrup. Yield was $2.4 \mathrm{~g}$.

\subsubsection{Isolation of Sum of Glycosides}

For increase in completeness of extraction $25 \mathrm{~g}$ a plant material with a degree of crushing $3.0-5.0 \mathrm{~mm}$ extracted by boiled water in a ratio of 1:6 during $3 \mathrm{hr}$., three times. Water extracts united and evaporate before reception of the waterless dry rest. The rest browno-yellow colors, looking like dense syrup, at cooling hardens. Yield was $8.2 \mathrm{~g}(32.8 \% \mathrm{III})$. Further for reception sum of glycosides extract III three times solve by $96 \%$-ethanol. Ethanol extracts summarized and solvent drove away on potophom the evaporator. Have received 4.0 g (yield 16\% from air-dried weight) IV-sum of glycosides. Remains water-soluble part $(\mathrm{V})$, yield $4.0 \mathrm{~g}$ (16\% from air-dried weight).

\subsection{Reactions with DDT}

In a conic flask were placed $100 \mathrm{mg}$ extracts and $50 \mathrm{mg}$ DDT. Stirred at room temperature during 3 days, controlled by TLC, significant change was not, leave still for 7 days, results of TLC showed that content of DDT in reactionary mixture has decreased for $45 \%-50 \%$ in a case of extract II, in case of $96 \%$-ethanol extract on $50 \%$ $60 \%$.

\section{Conclusions}

Influence of a degree of crushing of plant raw material, value of the hydromodule and temperatures on process of extraction of ground up part of the plant Stevia was investigated. It was isolated Steviaside of $80 \%$ purity from plant of Stevia.

Interactions of individual water and ethanol extracts of Steviaside from ground up part of Stevia with chloroorganic pesticides (DDT, HCCH and TTCB) were studied. It was identified products of reforming of chloroorganic pesticides degradation by plant extract.

Interaction of water extracts of ground up part of plant Stevia with pesticide $\mathrm{HCCH}$ basically formed tetrachlorocyclohexadiene $(\mathrm{HCH})$ with the yield of $86.9 \%$ and in particularly formed of tri-, tetrachlorobenzenes. In a case of Steviaside $80 \%$ purity also observed formation of the $\mathrm{HCH}$ with the yield of $79.7 \%$. It was determined, that at interaction of water extract of plant Stevia with $\mathrm{HCCH}$ and DDT at presence of alkaloid Anabasine in a ratio of 2:1:1 occurs degradation $\mathrm{HCCH}$ up to $70 \%$ $80 \%$, and in case DDT on $25 \%-30 \%$. On the basis of research interaction of extracts isolated from of ground up part of plant Stevia with pesticides DDT, HCCH and TTBC it is possible to conclude, that most effective reagents for degradation of persistent chloroorganic pesticides are ethanol, aqueous ethanol, water extracts of Stevia and Steviaside of $80 \%$ purity isolated from the plant Stevia.

\section{Acknowledgements}

The research was made by financial support of the INTAS M3-7271.

\section{REFERENCES}

[1] T. A. Henry, "Chemistry of Plant Alkaloids (in Russian)," Translation from English, under Edition Acad. Rodionov, Goskhimizdat, Moscow, 1956, pp. 59-71.

[2] K. M. Shakhidoyatov, M. M. Khakimov, N. I. Mukarramov, N. K. Khidyrova, K. U. Khodjaniyazov and B. A. Urakov, "The Ways of Degradation of Proof Chlororganic Pollutants by Plant Extracts," 7th International Symposium on the Chemistry of Natural Compounds, Tashkent, 16-18 October 2007, p. 147.

[3] N. K. Khidirova, K. M. Shakhidoyatov and N. I. Mukarramov, "Detoxification of Chloroorganic Pesticides by Extracts of the Elevated Part of Plant Stevia," 11th International Symposium on Natural Product Chemistry, Karachi, 29 October-1 November 2008, p. 131.

[4] K. M. Shakhidoyatov, M. M. Khakimov, N. I. Mukarramov and B. A. Urakov, "The Use of Alkaloid Containing Plant Extracts for Detoxification of DDT," Materials of Mendeleev Congress, Moscow, 23-29 September 2007, p. 131.

[5] K. U. Khodjaniyazov, N. I. Mukarramov, N. K. Khidirova, M. M. Khakimov, B. A. Urakov, E. S. Brodsky and K. M. Shakhidoyatov, "Degradation and Detoxification of Persistent Organic Pollutants in Soils by Plant Alkaloid Anabasine," Journal of Environmental Protection, Vol. 3, 
No. 1, 2012, pp. 97-106. doi:10.4236/jep.2012.31012

[6] K. Morita, M. Ogata and T. Hasegawa, "Chlorophyll Derived from Chlorella Inhibits Dioxin Absorption from the Gastrointestinal Tract and Accelerates Dioxin Excre- tion in Rats," Environmental Health Perspectives, Vol. 1091, No. 3, 2001, pp. 289-294.

doi:10.1289/ehp.01109289 